\title{
Automatic Question Paper Generator System
}

\author{
Fenil Kiran Gangar \\ Department of Information \\ Technology \\ K. J. Somaiya College of \\ Engineering \\ Vidhyavihar, Mumbai-77
}

\author{
Hital Gopal Gori \\ Department of Information \\ Technology \\ K. J. Somaiya College of \\ Engineering \\ Vidhyavihar, Mumbai-77
}

\author{
Ashwini Dalvi \\ Department of Information \\ Technology \\ K. J. Somaiya College of \\ Engineering \\ Vidhyavihar, Mumbai-77
}

\begin{abstract}
Information and intelligence are two vital columns on which development of humankind rise and knowledge has significant impact on operating of society. Student assessment is a crucial part of teaching and is done through the process of examinations and preparation of exam question papers has consistently been a matter of interest. Present-day technologies assist the teacher to stock the questions in a computer databases but the problem which emerges is how the present day technologies would also assist the teachers to automatically create the variety sets of questions from every now and then without worry about replication and duplication from the previous exam while the question bank keeps growing, so a non-automatic path for conniving a exam paper would not be able to serve to this need so in this paper we introduce an automated way which would permit the operation of conniving exam paper to be further well organized and productive and it would also aid in developing a database of questions which could be further classified for blending of exam question paper, currently there is no systematic procedure to fortify quality of exam question paper. Hence there appears a requirement to have a system which will automatically create the question paper from teacher entered description within few seconds. In this paper we have implemented a modern evolutionary path that is able to manage multi-constraints issue along with creating question papers for examinations in autonomous institutes from a very vast question bank database. This paper describes the utilization of randomization algorithm in an Automatic Question paper Generator System which has been implemented specially for autonomous institutes. The endeavor needed for generating question paper is diminished after the implementation of this advanced system and because of this advanced system there is no obligation for humans to ponder and employ time which can be utilized on some additional important duty instead of designing question paper.
\end{abstract}

\section{Keywords}

Questions Selection, Question Paper Generation, Difficulty level, Random logic, PDF file, Question paper format, pattern composer, question aggregator

\section{INTRODUCTION}

\subsection{Examinations in Autonomous Institutes}

Examinations predominantly use question papers as a vital constituent to discover the caliber of students. A good exam gives all students an equal opportunity to fully demonstrate their learning. The National Board of Accreditation (NBA),India ${ }^{[12]}$ states that Autonomous institutes should encourage the standard of teaching, selfanalysis and responsibility in higher education and promote the Institutions in perceive their educational aim, embrace education exercises that accredit them to yield appreciative quality professionals and to aid them in ceaselessly bestowing to the area of education through transformation \& research. Assessment is one or more activity that recognizes, gather, and construct data to assess the fulfillment of Course outcome and program Outcomes. Automatic Question paper generator system considers question paper creation as its fundamental activity, and the caliber of questions is the key in enhancing examination standard, which depend on intelligent and random choice of a set of questions.

\subsection{Teacher's role and responsibility}

Producing exam questions is challenging, monotonous and time consuming for teachers. Usually the teachers retain their own question banks in some form which aids them compose future exams question papers. In autonomous institutes there are some rules and regulations which are to be practiced by the teachers. They are as follows:

- $\quad$ To add variety to student learning

- To motivate students to study

- To provide statistics for the course or institution

- To facilitate students' choices

- Consider the point value of different question types.

- Creating objective test questions

\subsection{Examination pattern followed in Autonomous institutes}

The key point kept in mind while designing a question paper for exams in autonomous institute focuses on achieving the course outcomes. Knowledge of students in autonomous institutes is assessed based on various parameters which include Online Multiple choice question quiz, presentations, home assignments, mini projects, followed by the midterms and end terms. Following Table shows comparison of University exam pattern with Autonomous exam pattern.

Table 1: Table of Comparison for Exam Patterns

\begin{tabular}{|l|c|c|l|l|l|}
\hline \multicolumn{3}{|c|}{ University pattern } & \multicolumn{3}{c|}{ Autonomous pattern } \\
\hline $\begin{array}{l}\text { Intern } \\
\text { al } \\
\text { exam }\end{array}$ & $\begin{array}{c}\text { Extern } \\
\text { al } \\
\text { exam }\end{array}$ & $\begin{array}{c}\text { Tota } \\
\text { Internal }\end{array}$ & $\begin{array}{l}\text { External } \\
\text { Assessment }\end{array}$ & $\begin{array}{l}\text { Assessme } \\
\text { nt }\end{array}$ & 1 \\
& & & & \\
\hline
\end{tabular}




\begin{tabular}{|c|c|c|c|c|c|c|}
\hline $\begin{array}{l}\text { Unit } \\
\text { test }\end{array}$ & $\begin{array}{l}\text { Semest } \\
\text { er } \\
\text { exam } \\
80 \\
\text { marks }\end{array}$ & $\begin{array}{c}100 \\
\text { mar } \\
\text { ks }\end{array}$ & $\begin{array}{l}\text { Unit } \\
\text { Test } \\
30 \\
\text { mark } \\
\mathrm{s}\end{array}$ & $\begin{array}{l}\text { Qui } \\
\mathrm{z} \\
10 \\
\text { mar } \\
\mathrm{k}\end{array}$ & $\begin{array}{l}\text { Semester } \\
100 \\
\text { marks } \\
\text { (scale } \\
\text { down to } \\
60 \text { marks) }\end{array}$ & $\begin{array}{l}100 \\
\text { mar } \\
\mathrm{ks}\end{array}$ \\
\hline
\end{tabular}

\subsection{Automation:}

Automation means to replace the manual operations with computer procedures and other machines. Automation is aimed at increasing productivity, manufacturing prowess. It also reduces costs, labor and eliminates human error ${ }^{[1]}$

Table 2: Showing comparison of Manual process and automated process of question paper generation

\begin{tabular}{|l|l|}
\hline \multicolumn{1}{|c|}{ Manual Paper Generation } & \multicolumn{1}{|c|}{$\begin{array}{c}\text { Automatic Question Paper } \\
\text { Generation }\end{array}$} \\
\hline Human process & Automated Process \\
\hline $\begin{array}{l}\text { Patterns or repetitions may } \\
\text { occur }\end{array}$ & $\begin{array}{l}\text { Totally random and unbiased } \\
\text { process }\end{array}$ \\
\hline $\begin{array}{l}\text { Low Security as chances of } \\
\text { paper leaking are high }\end{array}$ & $\begin{array}{l}\text { Higher Security as chances } \\
\text { of paper leaking are zero } \\
\text { precent }\end{array}$ \\
\hline $\begin{array}{l}\text { Slow as human labour } \\
\text { involved }\end{array}$ & $\begin{array}{l}\text { Faster due to computer } \\
\text { based automation }\end{array}$ \\
\hline $\begin{array}{l}\text { Less variety of different types } \\
\text { questions }\end{array}$ & $\begin{array}{l}\text { Huge variety of different } \\
\text { types of questions }\end{array}$ \\
\hline
\end{tabular}

Table 3: Showing Automated process being used in currently in autonomous institutes

\begin{tabular}{|l|c|}
\hline \multicolumn{2}{|c|}{ Automated process followed currently in Autonomous } \\
\hline Online Quiz for MCQ & $\checkmark$ \\
\hline Online submission for assignment & $\checkmark$ \\
\hline Online Submission of Lab write ups & $\checkmark$ \\
\hline Online Feedback System & $\checkmark$ \\
\hline
\end{tabular}

So there is need for a system that can generate exam question paper for the Autonomous institute

Thus we can concluded that by implementing the automation system for exam question paper generation will yield enhancement in phrase of controlled access to the resources, random creation of question papers and a secure platform.

\subsection{Question Paper Generation}

In today's current ambitious world, an examination plays a crucial role in checking the academic development of students and the era of information technology is now substituted by productive application of the technology. So producing utility from knowledge is crucial for development of society into an "Information Society". For various examinations conducted in a year in any academic course, teachers need to create variation of question papers as per the autonomous college guidelines and assessment requirements. It is very difficult for the teachers to cover all features of the course outcomes and evade duplication of questions in the succeeding exams. There is no systematic procedure and hence the quality of the question paper relies entirely on an individual teacher's experience and proficiency. At times, this entire element may degrade standard of the question paper. As per research, a quality question paper is a real combination of questions supervised by varied criteria such as difficulty level, distribution of marks across the question paper in form of paper pattern and the type of examination. The procedure involved in composition of an equitable examination paper by an independent is challenging and complex. Standard of the examination paper rely on diverse set of specifications so taking into account the distinct levels of learners is also a crucial parameter and the course outcomes also play a vital role in planning a systematic question paper. So associating the learning outcome of the subject to the examination paper is also a great job. With the profound dispersal of technology in the area of education, acquiring technology to smooth the technique of examination paper creation is a pure option and creation of extensively vast question bank and automatic exam paper generation furnishes a key provision to the issue encountered during the manual composition of examination papers. Automatic creation of examination paper yields a stage to create a well-organized examination paper and also the automation would smooth in incorporating many elements determining quality of a question paper. The structure presented in the next module is to automate the activity of examination paper generation. The system would be comprised of a cluster of questions upon which regulation would be implemented to create question paper. The structure is general and is not for any specific branch of learning. It seeks to furnish a generic procedure to the diverse requirement of distinct fields of study. This generic structure can be redesigned to all departments in colleges thus ease the assessment needs. Before the exam could be given to the student, teachers must compose the questions according to the modules covered for individual subject. A proficient question paper is habitually fit for usual students but it also encloses demanding items for clever students. Thus automatically creating question paper from a teacher's entered description using a semantically labelled question bank is the requirement of the hour in present day. Here we are implementing a system which accordingly creates the question paper from this semantically labelled question bank. Since the prevailing systems are stiff and absence of flexibility of aiding all types of labels, the produced question paper may not be completely range with its given outcomes. Our each stuff is defined with a range demonstrating that value should not be under the bottom value and not surpass the topmost value of the range. Also, it is rule base system which takes all the associations of the labels and creates solution based on the rule relevant.

\section{LITERATURE REVIEW}

The outcome of coaching and education can be attained by performing evaluation to compute student's intellectual levels and therefore the written exam is a method for teachers to validate student understanding and knowledge, as well as, to evaluate the degree to which students are able to adjust a learning thesis in a given environment. Evaluation through written examination is a conventional procedure but it is a universal test technique performed in almost of the educational colleges present day. Therefore, the question must be catering in following with the subject contents learned by students to attain learning outcomes. However, the technique of questions writing is very demanding task for the teacher. The state is getting more challenging when teacher try to 
compose fair quality and fair questions to evaluate diverse level of intellectual.

In 2006, Ittizar Aldabe et al ${ }^{[1]}$ made an attempt to create automatic questions called ArikIturri, the procedure was based on Corpora and NLP methods, and the information source for the system was the linguistically inspected real corpora, depicted in XML mark-up language. The benefit of the system was its capacity to exclude the ill developed questions.

In 2006, Li-Chun Sung et al ${ }^{[2]}$ presented a outline for Automatic Quiz Generation for worldwide English E-learning System from a given English text to evaluate learner. This was built on quiz creation system for understanding of text content. The question generator takes the pure semantic network and the information base of WordNet and Google to create questions for quiz

In 2010, Ming Liu et al ${ }^{[3]}$ presented automatic question generation for literature review writing support. He took the literature review as input word and then the selected syntactic and semantic characteristic of words were used for question generation, which were based on a specification question bank consisting of equal match pattern and question templates. However, the questions were not simple word based questions; they were based on groups like opinion, result, system, which evaluated the intellectual learning experience of the learner. Another close work done by them was GASKS, where the similar method was used for academic writing to create questions built on Graesser \& Person taxonomy, here the Citation Classification was finished with the aid of Naive Bayes Classifier

\section{- $\quad$ Prevailing Paper-based Systems}

The prevailing system for Question Paper creation needed human staff to chalk out questions that come in the question paper. Teachers select the questions according to the syllabus and pattern as prescribed by the college. The question paper then may be referred to a higher authority that has the final decision in these matters ${ }^{[14]}$

\section{- $\quad$ Restriction of Paper-based Systems}

As majority of human working method, this system agonizes due to bias. There might be few questions which are duplicated in most of question papers as the professor has a personal tendency towards them. So there is no assurance of virtuous randomly generated question paper. Other issue that may affect this system are non-availability of teachers and resources. Also the security of the system can be easily undetermined if grip over the person responsible for generating question papers is obtained. ${ }^{[14]}$

\section{Other limitations include:}
a) Insufficiency of storage space
b) Vulnerable to damage
c) Incapable document transportation
d) Indigent environmental credentials
e) Restricted collaboration
f) Modification problems

\section{CHALLENGES FOR MAKING AUTOMATIC QUESTION PAPER GENERATOR SYSTEM}

1. Course Outcome mapping

Course outcomes are statements that describe significant and essential learning that learners have achieved, and can reliably demonstrate at the end of a course or program. Mapping of questions with the Course outcomes is one of the important challenges faced while making Question paper. So Question paper validation is to be ensured to get desired standard from outcome attainment perspective as well as learning levels perspective

\section{No repetition of questions}

While making question paper many a times patterns or repetitions may occur. So to avoid this situation the challenge faced is to make use of such algorithms which keep track of questions and do not allow the repetition of questions.

\section{Chapter wise allocation}

As there are different types of exams like unit test and end semester exam, so each exam has different modules of chapters covered on which the question paper has to be generated. So challenge faced here is to make system such that it is able to allocate the question chapter wise or module wise for the respective exams.

\section{Analysis of database}

In order to effectively assess the students, the important step is to plan the question paper which covers all the vital components to test knowledge of student. One such taxonomy was presented by Bloom (1956), who described degree of learning to be classified into six unique domains, namely 1.Knowledge 2.Comprehension 3.Application 4.Analysis 5.Synthesis 6. Evaluation, the benefit of making questions based on Bloom's taxonomy prepares to make the questions that help to evaluate learning ability of the students, to achieve this thing we have to design our database according to Bloom's taxonomy which will cover all types of questions and challenge faced there is to segregate the questions in the question bank database as per their types defined by the Bloom's taxonomy.

\section{Formatting of paper}

The generated questions from the system are to be presented in proper format or proper exam template. So the challenge faced is how to format the layout of the paper in the required style and in a compatible format.

\section{Paper pattern}

It is very important to know the question paper pattern and Marks allocation Scheme. So while designing the question paper the challenge is that the system should give flexibility in choosing the desired paper pattern and allocating marks to each question in paper

\section{IMPLEMENTATION}

The Automatic Question Paper Generator System is developed and built up using Java programming language. The fully functional system has reserves of courses, questions and patterns of question papers. It then executes the algorithm on the stocked question set and generates the question paper in PDF format.

\section{Modules in Automatic Test Paper Generator:}
a) Login Module
b) Administrator Module
c) User Module
d) Subject module
e) Exam type selection module 

f) Paper pattern module
g) Priority assignment module

A. Login Module: Login Module is divided into two parts as user module and administrator module. In login module, administrator as well as staff member will enter their credentials i.e. Login id and Password to access the system.

B. Administrator Module: Administrator module has two major roles: Staff Management and Category Management.

1. Staff Management: Admin of system will enter his credentials and then he will add faculty member to the system who have right to generate question paper and give rights to faculty members to add/update questions and generate paper.

2. Module Management : Admin will manage module according to the Department

C. User module: Normal user can login through this and generate the question paper as per his requirements.

D. Subject Module: It comprises of list of subject available for selection to the user. The user can put the initials of subject and can select the subject from list in order to generate the question paper

E. Exam type selection module: In this module user gets the option to select the type of exam for which he wants to generate the question paper. The exam type comprises of unit test one and two which are of 30 marks and final end semester exam which is of 100 marks

F. Paper pattern module: In this module user has to enter the distribution of marks according to the main question and sub question

G. Priority assignment module: In this module user has to assign priority to the question number in form of tags like easy, medium and difficult question. As per the priority assigned by the user the question are randomly fetched from the question bank database and displayed to the user.

Steps Involved in Automatic Question paper generator system are as follows-

1. Admin Login: Admin will be provided with the login ID and password, after registering to the system. After the successful login admin can enter the question in database according to unique key such as paper code and subject name this question will be stored in the database in the form of question bank.

2. Question Insertion: Admin can insert as many questions as he can according the syllabus requirement of the college. The questions will be classified according to marks allocated, level of difficulty i.e. priority.

3. Subject and exam type selection

4. Difficulty Choosing: Admin will decide the level of difficulty i.e. Easy, Moderate, Difficult.

5. Random Paper Generation: Questions are selected according to the level of difficulty.
6. PDF File Creation: The question generated are converted into the format of question paper and then transformed into PDF file.

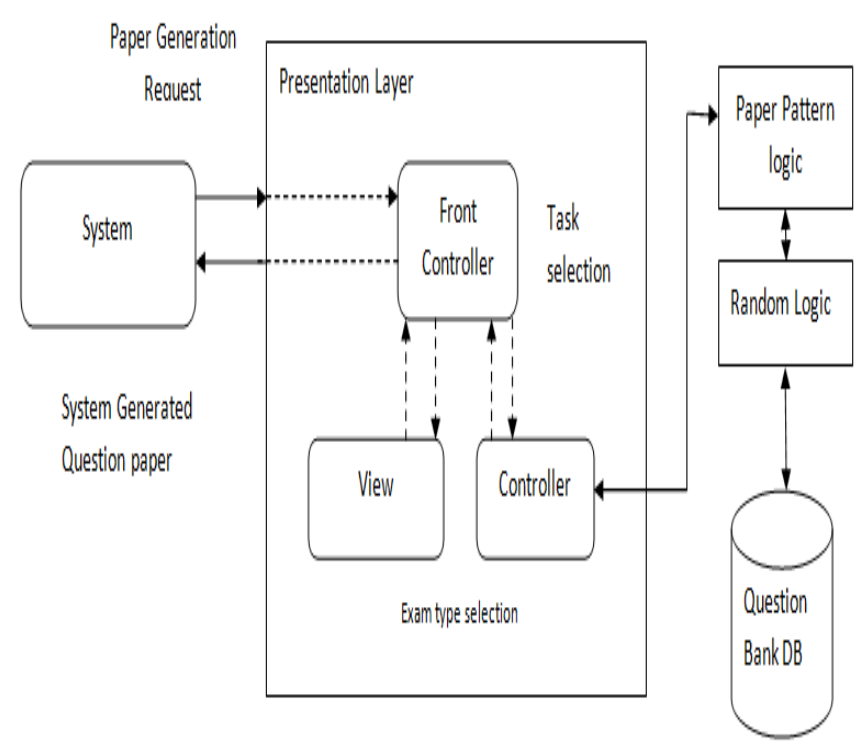

Figure 1: Represents MVC Architecture of System

\section{IMPLEMENTED ALGORITHM}

For $\mathrm{N}$ number questions accessible in question bank database following are the steps ${ }^{[14][15]}$

1. Generate a List ' $L$ ' number of $\mathrm{N}$ elements

2. Generate a random number ' $n$ ' such that $1<=n$

3. If $n \in L$ then go to Step 2 else reserve $n$ in the List

4. Choose a question from question bank database corresponding to $\mathrm{n}$, whose flag==true

5. For the question, set flag=false

\section{FEATURES AND BENEFITS}

Following are few of the characteristic of the Automatic Question Paper Generation System:

1. Simple user interface which increase the smooth the process of updating data.

2. Generates and develops the well formatted question Paper in a matter of few seconds.

3. Question category can be knowledge-based, Memory-based, Logic-based, or application-based.

4. Questions can be comfortably modified.

5. User can generate test papers randomly and instantly, thus saving a lot of time.

6. Algorithm enables randomization of questions.

7. A new question can be added to the database at any instance and different sets of test papers could be generated without any limitation.

8. With the use of this system for exam paper generation there are zero chances of exam paper getting leaked as paper can be generated few minutes before the exam.

The Automatic Question Paper Generation System delivers diverse benefits to the user when compared to the traditional system. 


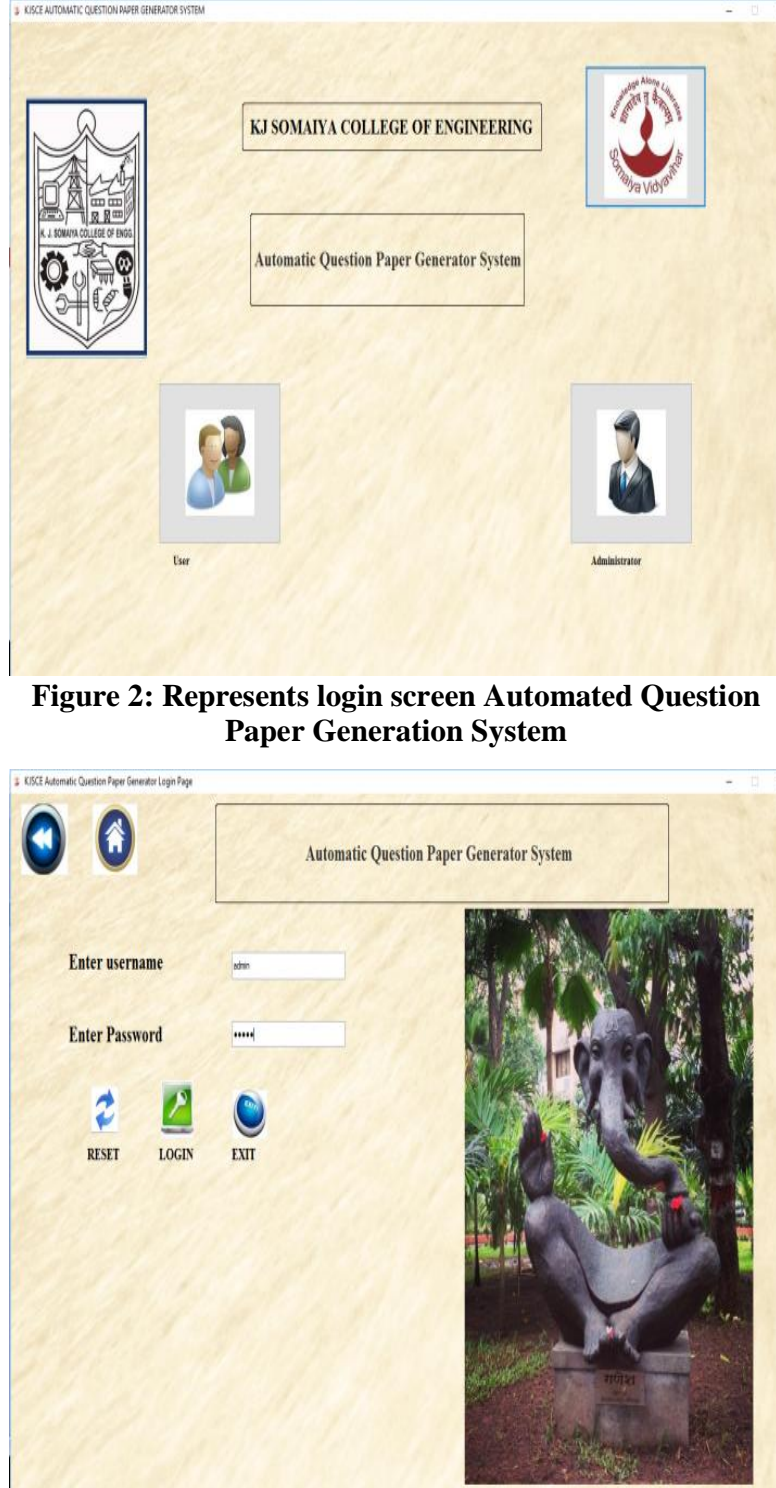

Figure 3: Represents login page of the admin user.

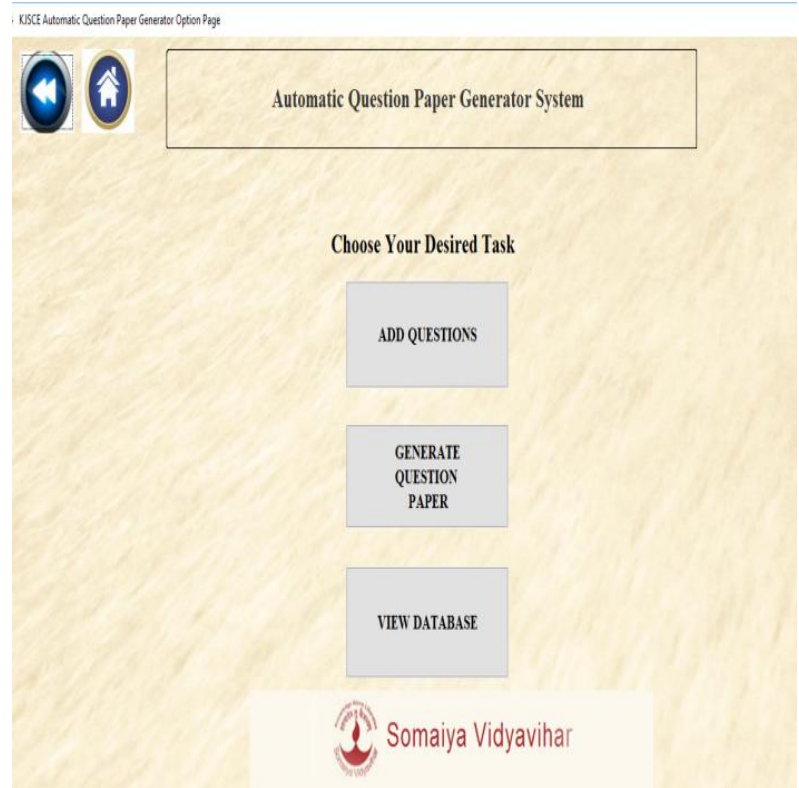

Figure 4: Represents the task selection page

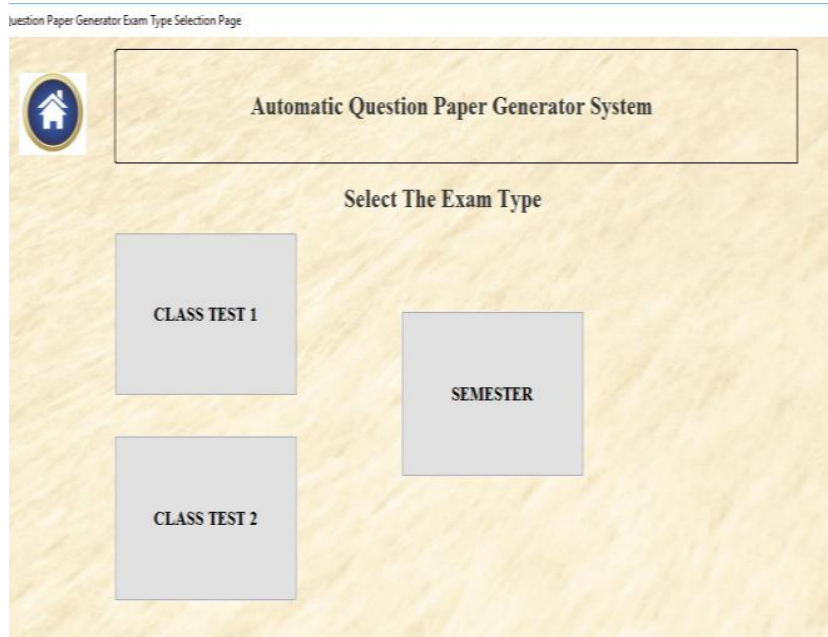

Figure 5: Represents the exam type selection page.

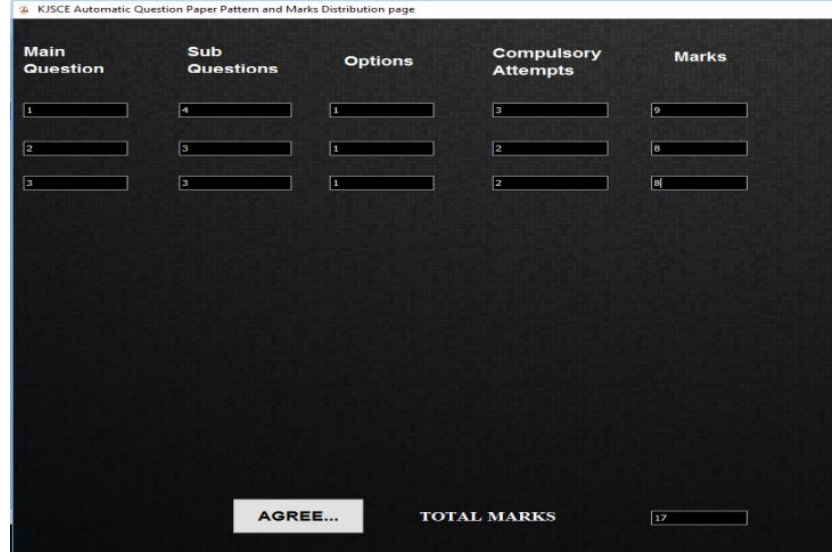

Figure 6: Represents the exam paper pattern page.

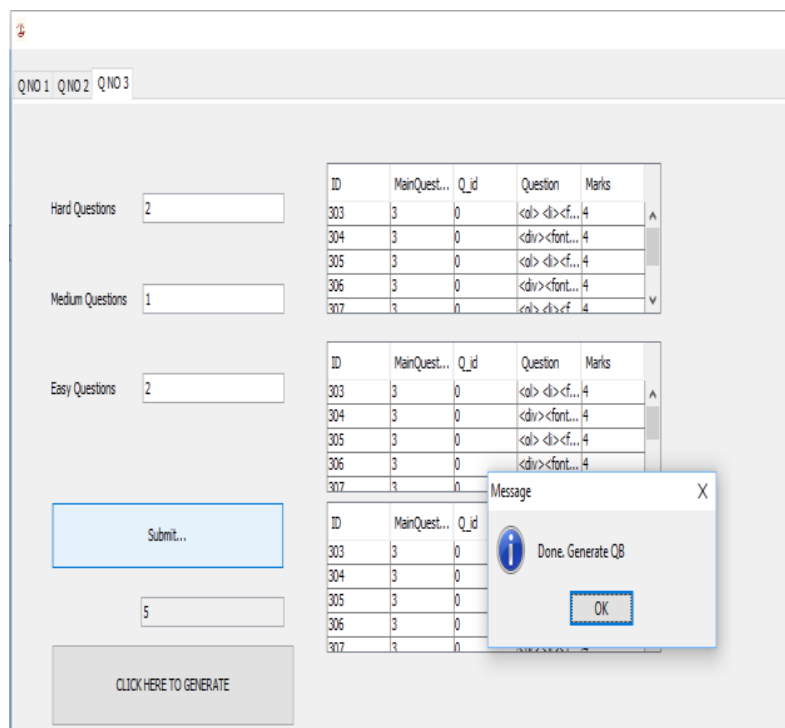

Figure 7: Represents the priority assigning and question paper generation page.

\section{CONCLUSION}

Assessment plays a vital role in teaching learning process and aligning assessment to the learning outcomes of the course is an important aspect. Question selection difficulty has been modeled as a multi-constraint optimization issue that aims at generating question papers fulfilling many constraints said by the paper setter. The implemented system tries to address the 
above mentioned issues in an efficient way. The implemented work narrates an automated system that heads away from the traditional process of paper generation to an automated process, by giving controlled entry to the resources that is attained by involving users and their roles in the colleges. We have also considered the significance of randomization in the process of paper generation. Our system has used a logical algorithm which is absolutely randomized in nature and avoids duplication of questions. Hence the resultant automated system for Question Paper Generation will yield enhancement in phrase of controlled access to the resources, random creation of question papers and a secure platform.

\section{REFERENCES}

[1] ItziarAldabe, Maddalen Lopez de Lacalle, MontseMaritxalar, Edurne Martinez2, and LarraitzUria, "ArikIturri: An Automatic Question Generator Based on Corpora and NLP Techniques", ITS 2006, LNCS 4053, pp. $584-594,2006$

[2] Li-Chun Sung, Yi-Chien Lin, Meng Chang Chen, "The Design of Automatic Quiz Generation for Ubiquitous English ELearning System", 2006.

[3] Ming Liu, Rafael A. Calvo and VasileRus, "Automatic Question Generation for Literature Review Writing Support" (2010)

[4] KapilNaik, ShreyasSule, ShrutiJadhav and Surya Pandey, "Automatic Question paper Generation System with help of randomization algorithm" IJETR, V, Issue 12, pp.1-3, Dec 2014.

[5] Vijay KrishanPurohit', Abhijeet Kumar', AsmaJabeen, SaurabhSrivastava, R H Goudar, Shivanagowda, "Design of Adaptive Question Bank Development and
Management System", International Conference on Parallel, Distributed and Grid Computing, 2012.

[6] VasileRus, ZhiqiangCai, Arthur C. Graesser Experiments

[7] Dan Liu, Jianmin Wang and LijuanZheng, "Automatic Test Paper Generation Based on Ant Colony Algorithm," Journal of Software, no. 10, October 2013

[8] Ashok Immanuel and Tulasi.B, "Framework for Automatic Examination Paper Generation System," International Journal of Computer Science Trends and Technology, Jan - March 2015

[9] SurbhiChoudhary, Abdul Rais Abdul Waheed, ShrutikaGawandi and Kavita Joshi, "Question Paper Generator System," International Journal of Computer Science Trends and Technology, issue 5, Sept - Oct 2015.

[10] PritaPatil and KavitaShirsat, "An Integrated Automated Paperless Academic Module for Education Institutes," International Journal of Engineering Science Invention Research and Development, , issue IX, March 2015.

[11] https://en.wikipedia.org/wiki/Automatic_test_pattern_ge neration

[12] http://www.nbaind.org/views/Home.aspx

[13] SheetalRakangor and Dr. Y. R. Ghodasara, "Literature review of Automatic Question Generation System", IJSRP, Issue 1, pp.346-350, Jan 2015.

[14] RohanBhirangi, SmitaBhoir "Automated Question Paper Generation System”, ijermt, 2278-9359,April 2016.

[15] Wikipedia(2010a).Randomization. http://en.wikipedia.org/wiki/Randomization 